\title{
POLÍTICAS EDUCACIONAIS E A RESISTÊNCIA ESTUDANTIL
}

\section{APRESENTAÇÃO}

\begin{abstract}
Além da opressão do governo, as pessoas com quem deveríamos contar indo contra nossos direitos? Às pessoas que querem nossa desistência, só um recado: NÃO TEM ARREGO!

(página de uma ocupação na zona leste de São Paulo, in: CAMPOS; MEDEIROS; RIBEIRO, 2016, p. 185).
\end{abstract}

No final de 2015, estudantes do Ensino Médio e do Fundamental II das escolas públicas da Rede Estadual de São Paulo entraram em luta contra a "Reorganização Escolar" imposta pelo governo estadual de Geraldo Alckmin.

O processo de mobilização iniciou-se com manifestaçôes de descontentamento e indignaçáo dos estudantes nas redes sociais e se alastrou rapidamente, com abaixo-assinados, protestos, passeatas e, finalmente, ocupaçóes de escolas. Durante as ocupaçôes, os estudantes organizaram aulas públicas nos diferentes bairros, promoveram shows de solidariedade e bloqueios de ruas, rompendo o silêncio e o descaso dos meios de comunicação tradicionais.

Poucas vezes, na história social recente, um movimento "soube utilizar espectro tão grande de táticas e se metamorfosear em tão curto espaço de tempo", contar com o apoio e a simpatia da população e, sobretudo, forjar novas práticas sociais, uma nova sociabilidade no processo de luta, a ação coletiva autônoma e horizontal (CAMPOS; MEDEIROS; RIBEIRO, 2016, p. 15-16).

Esse processo que mudou radicalmente o debate educacional no país teve início no dia 23 de setembro, quando os estudantes e seus pais foram surpreendidos com notícias sobre a decisão do governador de transferir centenas de milhares de alunos entre escolas da rede pública estadual, mudar os ciclos atendidos em mais de 700 escolas e fechar quase uma centena delas. Esse era o denominado programa de "Reorganização Escolar".

Sem debate público transparente, sem consultas aos principais envolvidos - às escolas e seus professores e alunos —, sem diagnóstico prévio que fundamentasse a amplitude das mudanças pretendidas e sua alegada vinculação à melhoria da qualidade, o projeto propunha unilateralmente uma verdadeira megaoperação de reestruturação, com impacto na atividade profissional de milhares de professores e sem qualquer garantia do uso dos prédios públicos para outras

DOI: 10.1590/ES0101-73302016171219 
atividades educacionais. Tudo isso quando o Estado deveria estar discutindo a regulamentação da gestão democrática em sua rede, conforme determina o art. $9^{\circ}$ da Lei no 13.005/2015 - Plano Nacional de Educação (BRASIL, 2014).

A inconsistência dos argumentos oficiais e a ausência de transparência sobre os critérios que levaram à escolha das escolas a serem reorganizadas ou extintas contribuíram para o aumento das preocupaçóes e o descontentamento geral. Segundo a Administração, havia vagas ociosas nas escolas. Tal afirmação se baseava na alegada redução de cerca de 2 milhóes de alunos, nos últimos 17 anos, na rede estadual. Argumentava, também, com fundamentação em estudo elaborado pela Coordenadoria de Informação, Monitoramento e Avaliação Educacional (Cima), órgão da Secretaria Estadual de Educação (SEE-SP), que "sob a ótica da aprendizagem" a separação por ciclos favoreceria o desempenho superior dos alunos (SECRETARIA DA EDUCAÇÃO DO ESTADO DE SÃO PAULO, 2015).

O referido estudo da Cima só veio a público muitas semanas após o anúncio do processo de reorganização, em resposta a dezenas de manifestaçóes críticas de instituiçóes de ensino e pesquisa, universidades, escolas de pedagogia e de licenciaturas, e entidades representativas do campo educacional. O governo sequer o publicou em seus canais oficiais, sendo que o texto veio a público no jornal O Estado de S. Paulo, que o obteve somente após recorrer aos mecanismos da Lei de Acesso à Informação. Até então, tratava-se de uma política de enorme impacto que, além de decidida unilateralmente, náo contava sequer com um documento técnico que a justificasse.

O estudo "Análise da política pública de Reorganização Escolar proposta pelo governo do Estado de Sáo Paulo", desenvolvido por professores do bacharelado e do Programa de Pós-graduação em Políticas Públicas da Universidade Federal do ABC (UFABC), analisou os pressupostos e conclusóes do estudo da Cima e identificou ausência de rigor científico, falhas elementares que decorriam da análise baseada em uma única variável de desempenho - o número de ciclos existentes em cada escola - , ignorando todos os demais elementos amplamente documentados na literatura da área e que incidem sobre o resultado de cada escola nas avaliaçōes externas (tais como o índice socioeconômico dos estudantes, a situação dos professores, o número de alunos por sala etc.). Os autores se propuseram, então, naquele momento, a qualificar e aprofundar o embasamento técnico da análise, aumentar a disponibilidade de informação e ampliar o debate público sobre a reorganização, de modo a propiciar e estimular a participação de toda a comunidade acadêmica e escolar na avaliação das reformas propostas (PÓ et al., 2015).

Enquanto isso, o movimento dos estudantes crescia. Durante seis semanas, entre setembro e novembro de 2015, os alunos foram às ruas centenas de vezes para protestar contra as medidas da "reorganização", às vezes com a participção de pais e professores. Pelos levantamentos realizados, que não foram exaustivos, houve mais de 163 protestos. Ocorreram manifestaçóes em pelos menos 63 cidades do 
estado, com protagonismo intenso do interior e em todas as regióes da cidade de Sáo Paulo. No final de novembro, a intensidade das ocupaçóes aumentou e atingiu uma média de oito escolas ocupadas por dia. No total, mais de 200 escolas foram ocupadas durante o processo (CAMPOS; MEDEIROS; RIBEIRO, 2016).

Uma das principais características da mobilização foi sua heterogeneidade: cada escola apresentou uma dinâmica política própria. Os secundaristas receberam apoio e solidariedade de diferentes grupos políticos - estudantil, sindical, partidário ou do movimento popular - , mas mantiveram a postura autônoma ao longo de todo o processo de mobilização. Essa autonomia, o cuidado com o espaço público da escola e a criatividade nos métodos de luta desmontaram os aparatos de repressão e possibilitaram que o movimento ganhasse simpatia de amplos setores da sociedade.

O movimento também contrariou uma das suposiçóes da fala governamental, presente às vezes na literatura educacional, que é a ideia de que devido à precariedade da escola pública e ao alegado descompasso curricular do ensino médio face às expectativas juvenis, os estudantes refletiriam um sentimento de não pertecimento e até de desprezo em relação à escola e aos professores. O que se viu foi o oposto: os alunos - apesar da precarizaçáo das condiçóes de ensino e trabalho nas escolas - mantêm uma relaçáo positiva com a escola pública, nela reconhecem um fundamental espaço de aprendizagem e de sociabilidade, e por isso se mobilizaram para salvá-la. Lutaram contra a precarização do ensino; contra a falta de bibliotecas, de laboratórios destinados ao ensino das ciências e das artes, de espaços para desenvolvimento do esporte e das atividades artísticas; mobilizaram-se contra a jornada excessiva e o baixo salário de seus professores, a ausência de tempo destinado às atividades lúdicas e culturais; denunciaram a baixa qualidade da alimentação que lhes é servida. Enfim, reinvindicaram o direito constitucional à universalidade de uma educação de base de igual qualidade, comum a todos os brasileiros, com respeito à diversidade de posiçóes e de interesses de estudantes, professores e comunidades.

Outro aspecto presente nos registros documentais e ressaltado na incipiente literatura sobre o assunto é que a percepção sobre a escola e seu espaço foi modificada com a ocupação. A permanência dos estudantes no espaço escolar por longos períodos propiciou-lhes um processo de apropriação da escola que é pública. A diversidade de experiências alimentou de sentidos inovadores o próprio significado do que é público na escola. A resistência à política autoritária e burocrática do governo estadual mostrou à população que a escola não é do governo de plantão, a escola é pública; cabe ao Estado assegurar condiçóes adequadas de funcionamento mas sua qualidade também depende da capacidade de ser apropriada pelo público, por professores, estudantes, pais e comunidade. Mostraram que cada escola pode ser uma experiência única, ainda que voltada a alguns objetivos sociais comuns.

Os mutiróes de limpeza e o cuidado na manutenção e conservação do patrimônio público contribuíram para uma visão da escola como espaço dos estu- 
dantes, "por direito", para sua apropriação simbólica. O contraste entre os espaços destinados a todos e os espaços restritos à gestão, aos quais dificilmente tinham acesso no cotidiano escolar, suscitou questóes relativas ao padráo de gestão nas escolas estaduais, à falta de transparência na gestão da educação estadual, à ausência da gestão democrática e participativa. O que os levou também a reivindicar a existência de grêmios estudantis independentes, reuniōes regulares do Conselho de Escola e da Associação de Pais e Mestres (APM) para as tomadas de decisão, além de novos canais de participação na gestão das escolas, como indicam as fontes relatos e depoimentos dos estudantes, fotos e filmografia dos acontecimentos (CAMPOS; MEDEIROS; RIBEIRO, 2016).

Os desafios e dificuldades de convivência e da autogestão democrática também estimularam descobertas positivas, que vieram a promover mudanças na lógica das relações entre os estudantes e entre esses e as escolas e suas comunidades. Como indicam os registros das ocupaçóes nas redes sociais, a ruptura com relação à dinâmica das relações de gênero anterior à ocupação talvez tenha sido um dos processos mais marcantes. A atuação das meninas no movimento - evidenciada, em particular, nas imagens fotográficas dos trancamentos de rua e nos enfrentamentos com a polícia - mostram o protagonismo das mulheres. A convivência e suas atividades formativas contribuíram para um novo olhar sobre a diversidade, sobre as questôes de igualdade de gênero e da comunidade de lésbicas, gays, bissexuais, transgêneros e travestis — LGBT (CAMPOS; MEDEIROS; RIBEIRO, 2016).

O recuo do governo, em novembro, e o anúncio da suspensão da "reorganizaçáo" em pronunciamento público pelo governador consolidou a vitória do movimento dos estudantes. A publicação do decreto $n^{\circ}$ 61.692/2015 no Diário Oficial (SÃO PAULO, 2015) marcava uma grande conquista, poucas vezes vista em mais de 20 anos de governo tucano. Aos poucos e de modo diferenciado, impelidos pela violência ou pela avalição autônoma do movimento, em meio a hesitações e acordos com as diretorias das instituições, os estudantes foram desocupando as suas escolas. Mas a luta não terminara, eles sabiam.

A experiência de ocupação das escolas em São Paulo, por sua vez, espelhada nas experiências dos estudantes chilenos e argentinos, alcançou outros estados do país. Os estudantes goianos começaram a ocupar as escolas em dezembro e, em janeiro de 2016, o número de escolas ocupadas chegou a 27. Em Goiás, o movimento lutava contra um projeto de consequências ainda mais graves para a escola pública: a ideia de entregar parte da gestão das escolas, particularmente a contratação de professores e funcionários, a Organizaçóes Sociais (OSs). Ocupaçóes ocorreram também no Rio de Janeiro, no Rio Grande do Sul, no Ceará, além de outros Estados, em solidariedade à greve dos professores da rede estadual, contra o controle ideológico das escolas, em favor de uma alimentação escolar adequada etc.

Em São Paulo, o novo Secretário da Educação, o desembargador José Renato Nalini, apesar de apontar para uma nova fase de diálogo, tomou medidas excluindo 
a participação dos estudantes no debate sobre a reorganização, com a criação de uma instância denominada Frente de Instituições Públicas pela Educação do Estado de São Paulo (Fipesp), que reúne somente instituiçóes do campo jurídico, além da presidência da Assembleia Legislativa, com o propósito de discutir as reformas educacionais no estado (REDE ESCOLA PÚBLICA E UNIVERSIDADE, 2016).

Tem início, então, uma nova fase de informações desencontradas sobre os planos da Administração; a dinâmica de fechamento de salas de aula, as dúvidas sobre os efeitos da reorganização iniciada em 2015 sobre a oferta de vagas em 2016 e o que passou a ser apontado por alguns sujeitos como uma "reorganização disfarçada" ou "silenciosa".

Com salas sendo fechadas e a superlotação das turmas, tanto no Ensino Fundamental (I e II) como no Ensino Médio e na Educação de Jovens e Adultos, sendo autorizada em Portaria da SEE-SP, desconfiava-se que algumas dimensóes do projeto continuavam a ser executadas de outra maneira, apesar da suspensáo administrativa e da decisão judicial que determinou o cancelamento em definitivo.

$\mathrm{Na}$ segunda metade de 2016, o golpe institucional e a nova conjuntura política do país, marcada pelas investidas contra as conquistas civilizatórias da Constituição de 1988 por meio principalmente da Proposta de Emenda Constitucional $n^{\circ}$ 241/2016 (BRASIL, 2016b) e da Medida Provisória n 746/2016 (BRASIL, 2016a), que reformam radicalmente a estrutura e os propósitos do ensino médio, levariam a uma nova onda de ocupaçóes escolares, dessa vez ampliada substancialmente em seu número e também pela participação de institutos e universidades federais, tema tratado no editorial desta edição de "Educação \& Sociedade".

A luta estudantil e a indignação contra a violência perpetrada pela política deu frutos também quanto à organização de outros setores. No final de 2015 , um grupo de professores e pesquisadores das diversas universidades públicas de São Paulo (UFABC, Universidade Federal de São Paulo - UNIFESP, Universidade Federal de São Carlos - UFSCar, Universidade de São Paulo - USP, e Universidade Estadual de Campinas - UNICAMP), estaduais e federais, além do Instituto Federal de Educação Tecnológica de São Paulo (IFET), levou à idealização e articulação do que viria a se denominar "Rede Escola Pública e Universidade", nascida com o "objetivo de realizar estudos, pesquisas e intervençóes, de modo a ampliar o debate sobre a qualidade de ensino na rede estadual de educação" (REDE ESCOLA PÚBLICA E UNIVERSIDADE, 2016, p. 2).

A organização desse Dossiê objetivou apresentar, em primeiro lugar, os resultados de pesquisas e análises desenvolvidas por alguns dos participantes desse grupo de professores da "Rede Escola Pública e Universidade". Trata-se de um reconhecimento à qualidade e à importância dessa articulação, uma das melhores novidades de colaboração acadêmica entre pesquisadores e entre esses e a escola pública surgida no período recente, como poderá ser visto diretamente na leitura dos textos. 
Sáo estudos tanto sobre a dinâmica da rede estadual e o processo de reorganização como sobre o movimento de resistência dos estudantes das escolas e suas implicaçóes para o conjunto da vida social e, em particular, para as políticas públicas de educação. Em segundo lugar e de forma complementar, os três artigos finais do Dossiê pretendem propiciar, no âmbito do debate mais amplo sobre a temática da relação entre desigualdade social e desigualdade educacional, o desenvolvimento de reflexôes relacionadas à natureza e ao significado das políticas públicas atuais de democratização educacional no país, tema conexo ao dos artigos iniciais.

Fenando Luiz Cássio, Leonardo Crochik, Maria Clara Di Pierro e Sergio Stoco abrem o Dossiê com o texto "Demanda social, planejamento e direito à Educação Básica: uma análise da Rede Estadual de Ensino Paulista na transição 2015-2016" e discutem a política de atendimento às demandas escolares do governo estadual caracterizando-a como expressão de uma administração pública gerencialista e privatista. Utilizando-se de indicadores sociais e educacionais, eles mostram que, ao contrário dos argumentos apresentados pela SEE-SP, apesar de a redução da fecundidade em coortes da população incidir sobre a idade da escolarização obrigatória, as matrículas nas escolas públicas estaduais tendem à estabilidade, não havendo diminuição significativa das demandas que possa justificar o pretendido fechamento de ciclos e unidades escolares. Os dados apresentados confirmam também o aumento do número de alunos por classe em todas as etapas da Educação Básica estadual, contrariando as Diretrizes do Conselho Nacional de Educação e as boas condições de ensino e aprendizagem reivindicadas por estudantes e educadores.

No artigo "A dimensão espacial da escola pública: leituras sobre a reorganização da rede Estadual de São Paulo", Eduardo Donizeti Girotto analisa a proposta do governo paulista a partir de uma dimensão fundamental da escola pública: o seu enraizamento territorial. $\mathrm{O}$ autor indica que, ao tomar as escolas como entes abstratos, desconectados do seu entorno social, o governo promoveu, na prática, uma profunda mudança na relação socioespacial dos alunos e alunas entre si e com suas escolas. De forma instigante, o autor analisa como a luta dos estudantes trouxe à tona a dimensão territorial das escolas públicas, reafirmando-as como espaços de construção de identidades, diálogos e conflitos.

Em outra perspectiva, Lisete R.G. Arelaro, Márcia A. Jacomini e Sílvio R. G. Carneiro retomam a questâo da gestão democrática e examinam sua importância nas recentes reinvindicaçóes dos estudantes de São Paulo. Segundo os autores, os Grêmios, Conselhos Escolares e APM constituem-se como instituições fundamentais para a vida democrática nas escolas. Nessa direção, no texto "Participação e gestão 'democrática' na rede estadual paulista", eles analisam o campo jurídico-político da gestão escolar da abertura democrática até o avanço neoliberal, para, em seguida, discutirem as políticas de educação do Estado de São Paulo, desde a primeira "reorganização" de 1995. Tais políticas são caracterizadas 
por uma gestão empresarial, de caráter financeiro e pedagógico, que interfere e desvaloriza a gestão democrática nas escolas públicas estaduais.

Os dois artigos seguintes, "Ocupar e resistir: a insurreição dos estudantes paulistas", de Ana Paula Corti, Maria Carla Corrochano e José Alves da Silva, e "Escolas de luta, educação política: reflexóes sobre o sentido da ocupação das escolas públicas no Estado de Sáo Paulo”, elaborado por Carolina Catini e Gustavo Mello, tratam diretamente do movimento de ocupação das escolas da rede estadual paulista. A partir do exame de fontes documentais — publicaçóes na rede social, em jornais e revistas - e do diálogo com a literatura recente sobre o tema, o primeiro artigo enfatiza as mudanças na rede estadual de ensino que resultaram na crescente presença de adolescentes e jovens, bem como discute o sentido das tensóes e desencontros entre a escola e os segmentos juvenis, salientados nos estudos acadêmicos. Em seguida, analisa as ocupaçóes estudantis, entendendo-as como modalidade de ação coletiva que interroga as políticas educacionais e a cultura escolar a partir de novas estratégias e linguagens, distintas dos mecanismos tradicionais da democracia representativa.

$\mathrm{Na}$ mesma direção, o segundo texto se propóe a analisar o contexto político, econômico e educacional em que ocorre o movimento de ocupaçáo pelos estudantes, e a refletir acerca de suas contradiçóes e de seus potenciais formativos e organizativos, considerando a forma e os conteúdos da ação dos secundaristas à luz da crítica aos modos dominantes de educação escolar e a certas práticas políticas correntes no seio da esquerda.

Sob outra perspectiva, Mariana Lins de Oliveira e Luciana Rosa Marques, em "Políticas de Juventudes: história de vida, educação e resistência”, propóem identificar, a partir da história de vida de jovens pobres moradores das periferias do Estado da Paraíba, os modos como esses sujeitos criam estratégias de resistência expressas em maneiras de vivenciar a juventude e que se contrapóem aos processos de normalização oriundos das políticas governamentais. A pesquisa se detém mais especificamente nas histórias de vida de dois jovens, moradores da comunidade de São Rafael, em João Pessoa, e do município de Zabelê, pequena cidade do Cariri paraibano. Utilizando-se das formulaçóes teóricas de Michel Foucault na análise interpretativa, as autoras apontam que os jovens têm construído tanto modos de vida capturados pelos processos de normalização como também, em certa medida, desenvolvem "experiências de singularização ou de re(x)istência".

Monica Carvalho Magalhães Kassar, no artigo "Escola como espaço de desenvolvimento humano e a diversidade", tem o propósito de apresentar elementos para uma análise das possibilidades de desenvolvimento humano na escola. Para isso, examina as atuais políticas educacionais propostas para o acolhimento da diversidade e o contexto em que a diversidade afirma-se no âmbito legal. Com base em dados do Censo Escolar, a autora problematiza situaçóes encontradas em instituiçóes escolares consideradas representativas das diferentes formas de 
lidar com a diversidade, de modo a identificar desafios a serem superados para o alcance do desenvolvimento humano pleno nos espaços escolares.

Por fim, no artigo que fecha o Dossiê, "Escolarização de jovens e igualdade no exercício do direito à educação no Brasil: embates do início do século XXI", Marcio Pochmann e Eliza Bartolozzi Ferreira propóem discutir e examinar a concepção das políticas de democratização da escolarização dos jovens desenvolvida neste início do século. Argumentam que essas políticas sáo resultados de medidas de adequação da educação brasileira à lógica da competitividade instaurada no capitalismo global, com características marcadas pela busca de um suposto equilíbrio inclusão/exclusão vis-à-vis a histórica limitação das políticas voltadas para a igualdade dos direitos. Afirmam que, na análise da literatura internacional referenciada ao longo do texto, a questão central hoje não está mais na busca da igualdade, mas na luta contra a exclusão. Essa é a perspectiva de justiça social que orienta a educação no quadro da globalização econômica e cultural, a qual apresenta uma dinâmica mais acelerada na produção e circulação das mercadorias. Quadro esse que deixa o trabalho cada vez mais fragmentado em diversas ocupaçôes distribuídas na área dos serviços. Com base em estudo empírico e informações primárias do banco de dados do Instituto Brasileiro de Geografia e Estatística (IBGE), que interpretam a situação recente da escolaridade dos jovens de 15 a 29 anos de idade e suas taxas de ocupação na vida social, os autores consideram que a trajetória da democratização se revelou muito mais uma expansão quantitativa de matrículas em contextos escolares desiguais e empobrecidos, com trabalhadores desvalorizados como categoria profissional. Portanto, as políticas educacionais não conscretizaram uma estrutura para exercer, com igualdade, o direito à educação.

O Dossiê "Políticas Educacionais e a Resistência Estudantil", como se vê, articula análises específicas sobre a experiência vivida em São Paulo às dinâmicas mais amplas de pressão por democratizaçáo e transformação da escola pública. É uma contribuição de "Educação \& Sociedade" à compreensão das novas dinâmicas escolares, estudantis e do campo acadêmico que nascem em resposta ao perfil conservador e autoritário das recentes propostas de reformas educacionais. Desejamos uma ótima leitura e que o material aqui reunido possa servir à continuidade da aproximação entre a Escola Pública e a Universidade.

\section{Referências}

BRASIL. Lei n ${ }^{\circ} 13.005$, de 25 de junho de 2014. Aprova o Plano Nacional de Educação PNE e dá outras providências. Poder Executivo, Brasília, DF, 2014. Disponível em: <https:/www.planalto.gov.br/ccivil 03/ ato2011-2014/2014/lei/l13005.htm>. Acesso em: 03 dez. 2016.

. Medida Provisória no 746, de 22 de setembro de 2016. Institui a Política de Fomento à Implementação de Escolas de Ensino Médio em Tempo Integral, altera a Lei no 9.394, de 
20 de dezembro de 1996, que estabelece as diretrizes e bases da educação nacional, e a Lei no 11.494 de 20 de junho 2007, que regulamenta o Fundo de Manutençáo e Desenvolvimento da Educação Básica e de Valorização dos Profissionais da Educação, e dá outras providências. Poder Executivo, Brasília, DF, 2016a. Disponível em: <https:/www.planalto.gov.br/ccivil 03/ Ato2015-2018/2016/Mpv/mpv746.htm >. Acesso em: 18 nov. 2016

Proposta de Emenda Constitucional n 241, de 11 de outubro de 2016. Altera o Ato das Disposiçóes Constitucionais Transitórias, para instituir o Novo Regime Fiscal. Câmara dos Deputados, Brasília, DF, 2016b. Disponível em: <http://static. congressoemfoco.uol.com.br/2016/10/PEC-241-20162.pdf>. Acesso em: 18 nov. 2016.

CAMPOS, A.; MEDEIROS, J.; RIBEIRO, M. Escolas de luta. São Paulo: Veneta, 2016. (Coleção Baderna.)

PÓ, M.V.; YAMADA, E.M.K.; XIMENES, S.B.; LOTTA, G.S.; ALMEIDA, W.M. Análise da política pública de Reorganização Escolar proposta pelo governo do Estado de São Paulo. 2015. Disponível em: <https://blogdosalomaoximenes.files.wordpress.com/2015/12/ anc3a1lise-da-reorganizac3a7c3a3o-escolar-sp.pdf>. Acesso em: 02 dez. 2016.

REDE ESCOLA PÚBLICA E UNIVERSIDADE. Nota técnica: análise da resposta da Secretaria da Educação do Estado de São Paulo (Departamento de Planejamento e Gestão da Rede Escolar e Matrícula - DGREM) à Ação Civil Pública (ACP) movida pelo Ministério Público do Estado de São Paulo e Defensoria Pública do Estado de São Paulo, processo n. 1049683-05.2015.8.26.0053. jun. 2016. Disponível em: <http://www. observatoriodaeducacao.org.br/images/pdfs/nota.tecnica.\%20reorganizacao.2016.pdf $>$. Acesso em: 25 out. 2016.

SÃO PAULO (Estado). Decreto no 61.692, de 4 de dezembro de 2015. Revoga o Decreto no 61.672, de 30 de novembro de 2015. Poder Executivo, São Paulo, 2015. Disponível em: <http:/www.al.sp.gov.br/repositorio/legislacao/decreto/2015/decreto-61692-04.12.2015.

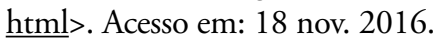

SECRETARIA DA EDUCAÇÃO DO ESTADO DE SÃO PAULO. Coordenadoria de Informação, Monitoramento e Avaliação Educacional. Escolas estaduais com uma única etapa de atendimento e seus reflexos no desempenho dos alunos. São Paulo, 2015. Disponível em: <https:// avaliacaoeducacional.files.wordpress.com/2015/12/reorganizac3a7c3a3o-das-escolas-em-spdoc-secretaria.pdf >. Acesso em: 25 out. 2016.

Carmen Sylvia Vidigal Moraes ${ }^{1}$ Salomão Barros Ximenes ${ }^{2}$

\footnotetext{
${ }^{1}$ Universidade de São Paulo, Faculdade de Educação - São Paulo (SP), Brasil.

E-mail: carmensvmoraes@gmail.com

${ }^{2}$ Universidade Federal do ABC, Centro de Engenharia, Modelagem e Ciências Sociais Aplicadas, Programa de Pós-graduaçáo em Políticas Públicas - Santo André (SP), Brasil. E-mail: salomaoximenes@gmail.com
} 